\title{
Variables Associated With Human Papillomavirus (HPV) Vaccine Acceptance by Men
}

\author{
Daron G. Ferris, MD, Jennifer L. Waller, PhD, Jeremiah Miller, Pratik Patel, \\ George A. Price, Lanier Jackson, and Courtesia Wilson
}

Objective: To determine correlates of human papillomavirus (HPV) vaccine acceptance for men.

Methods: A convenience sample of men aged 18 to 45 years read a one-page information sheet about HPV and the HPV vaccine, then completed a 29 -item questionnaire. $\chi^{2}$ tests were used to determine whether differences in demographic, sexual, and vaccine-related variables existed between levels of wanting the HPV vaccine.

Results: Positive correlates of HPV vaccine acceptance included higher education $(P<.0001)$; hispanic ethnicity $(P=.0003)$; wearing a seat belt most of the time $(P=.02)$; regular tobacco use $(P=$ $<.001)$; not being sexually active $(P=.0008)$; history of more than 10 female sexual partners $(P=$ $.0004)$; not having oral sex $(P=.045)$; extreme worry about vaccine side effects $(P<.0001)$; extreme concern about vaccine safety $(P<.0001)$; the importance of getting vaccines $(P<.0001)$; familiarity with HPV $(P<.0001)$; and extreme importance of receiving the HPV vaccine $(P<.0001)$.

Conclusions: Men with greater general education, high-risk behaviors, and knowledge about HPV are more likely to want the HPV vaccine. Focused educational efforts should facilitate even wider acceptance of the HPV vaccine by men. (J Am Board Fam Med 2009;22:34-42.)

In 2006, the US Food and Drug Administration (FDA) approved the quadrivalent human papillomavirus (HPV, types 6/11/16 and 18) L1 virus-like particle vaccine. This prophylactic vaccine prevents cervical, vaginal, vulvar, and perianal neoplasias, including anogenital condylomata. ${ }^{1-4}$ Based on epidemiologic data, the vaccine should reduce the incidence of cervical cancer by $70 \%$ and genital warts by $90 \%$. Universal protection is afforded when administered to people not previously exposed to the HPV types covered by the vaccine. Currently, the vaccine is approved for use in 9- to 26-year-old girls and women.

Many low-risk and high-risk types of HPV can also infect various anatomic sites in boys and men. ${ }^{5}$ The low-risk types of HPV cause recurrent respiratory papillomatosis or condylomata of the naso-

This article was externally peer reviewed.

Submitted 10 January 2008; revised 29 May 2008; accepted 3 June 2008.

From the Gynecologic Cancer Prevention Center (DGF); the Departments of Family Medicine and Obstetrics and Gynecology (DGF) and the Department of Biostatistics (JLW, GAP), Medical College of Georgia (JM, PP, LJ); and Paine College (CW), Augusta, Georgia.

Funding: none.

Conflict of interest: none declared.

Corresponding author: Daron G. Ferris, MD, Medical College of Georgia, 1423 Harper Street, HH-105, Augusta, GA 30912-3500 (E-mail: dferris@mcg.edu). pharynx. ${ }^{6,7}$ Anogenital warts are also caused by low-risk HPV types 6 and 11. High-risk HPV types cause precancers and cancer of the penis and anus. ${ }^{8-13} \mathrm{HPV}$ 16, a particularly virulent type, causes head and neck cancer. ${ }^{14,15}$ Just as with women, men experience significant morbidity and potential mortality from HPV-related diseases.

Women clearly benefit from receiving the HPV vaccine. One would assume men could also benefit by being vaccinated against low- and high-risk HPV types. Correlates of HPV vaccine acceptance have been identified for mid-adult women. ${ }^{16}$ However, correlates of HPV vaccine acceptance among men have not been described. The purpose of these analyses were to determine correlates of HPV vaccine acceptance among men.

\section{Methods \\ Population}

A convenience sample of 18 - to 45 -year-old men were recruited to participate in our study. Subjects were enrolled at various places in Augusta and Atlanta, Georgia, including a local military base, college campuses, fire stations, a university-based family medicine center waiting room, and from elsewhere in the community. Inclusion criteria included an interest to complete a brief questionnaire; being a man; 18 - to 45 -years-old; and an 
ability to read, write, and understand English. We did not exclude men based on a medical history of HPV-related disease or genital warts. The Medical College of Georgia Human Assurance Committee reviewed and approved (HAC File \#07 to 06 to 313) this study.

\section{Study Instrument}

Our survey was developed by initially modifying for male gender use an existing mid-adult woman's survey about the HPV vaccine. ${ }^{17}$ This similar version allowed for comparisons between the sexes. A diverse focus group of 7 men then read a gendermodified HPV information sheet before providing critical feedback about the survey. The HPV information sheet addressed HPV risk factors, prevention, infection sequelae, and the quadrivalent HPV vaccine. ${ }^{17}$ Suggestions from the focus group were used to revise the draft survey.

The 29-question survey was modified so it could be completed in 10 minutes or less. Questions addressed demographic data, history of sexually transmitted infections, sexual history and preference, lifestyles practices, attitudes toward vaccines in general, knowledge of HPV and the HPV vaccine, and men's reasons for wanting or not wanting to receive the HPV vaccine. True or false, yes or no, and multiple choice question types were included.

\section{Study Design}

The study was designed to determine correlates of HPV vaccine acceptance among 18- to 45-year-old men. Men appearing to be within the specified age range were asked to complete a brief survey about the HPV vaccine. Interested and eligible men read a letter of invitation and a 1-page information sheet about HPV and the vaccine. Men then completed the self-administered survey. To protect confidentiality, no subject specific identifiers were recorded on the surveys. Responses were returned in a sealed envelope. The same investigators (JM, PP, LJ, and $\mathrm{CW}$ ) administered all surveys and entered data. Men were not compensated for their participation. This study was conducted 14 months after FDA approval of the quadrivalent HPV vaccine for use in 9- to 26-year-old girls and women.

\section{Statistical Analysis}

Descriptive statistics were calculated on all variables. $\chi^{2}$ tests were used to examine whether differences in demographic, sexual, and vaccine-re- lated variables existed between levels of wanting to get the HPV vaccine (yes, no, or don't know). Statistical significance was assessed using an $\alpha$ level of 0.05 and all statistical analyses were performed using SAS software version 9.1.3 (SAS Institute, Inc., Cary, NC).

\section{Results}

Of approximately 650 men who were asked to volunteer, complete data were available for 571 men. Insufficient time to complete the survey and general lack of interest were the most common reasons for nonparticipation. Detailed demographic data have been previously published. ${ }^{18}$ However, in summary, most men were white $(61.0 \%)$ with at least a high school education (96.5\%) and younger than 30 years old (69.2\%). Approximately half $(52.1 \%)$ had a family income of less than $\$ 50,000$ per year and the majority $(86.6 \%)$ had some type of medical insurance. Almost two-thirds (64.2\%) were of the Protestant faith. Most men (63.6\%) were single and $94.9 \%$ claimed to be heterosexual. Nearly three-quarters (74.4\%) were sexually active and $83.1 \%$ had initiated sexual activity by the age of 18. Only $2.3 \%$ had a history of genital warts.

Of the 571 subjects, $33 \%$ wanted to be vaccinated against HPV, 27\% did not, and 40\% were undecided. ${ }^{18}$ We compared demographic data with $\mathrm{HPV}$ vaccine preference to determine correlates of vaccine acceptance among men (Table 1). Differences in wanting to get the HPV vaccine were found for various demographic variables, including age, race, education, martial status, wearing a seatbelt, and using tobacco. A greater percentage of men who did not want to get the vaccine were older $(P=.0009)$, black $(P=.0003)$, and had a lower education level $(P<.001)$. Men who were undecided about receiving the vaccine were more likely to be younger and white. Being a college graduate or Hispanic were positive correlates for vaccine acceptance. Men who were undecided about receiving the vaccine were more likely to be single and men who did not want the vaccine were most likely to be living with a partner $(P=.02)$. Men who want the vaccine were more like to wear their seatbelt most of the time $(P=.018)$. Regular use of tobacco correlated positively with vaccine acceptance $(P=$ $.001)$.

We also compared men's sexual history with HPV vaccine preferences (Table 2). Other differ- 
Table 1. Comparison of Demographics With Human Papillomavirus Vaccine Preferences

\begin{tabular}{|c|c|c|c|c|}
\hline \multirow[b]{2}{*}{ Variable } & \multicolumn{3}{|c|}{ Do You Want to Receive the HPV Vaccine? } & \multirow[b]{2}{*}{$P^{*}$} \\
\hline & $\begin{array}{c}\text { Yes } \\
(\mathrm{n}[\%])\end{array}$ & $\begin{array}{c}\mathrm{No} \\
(\mathrm{n}[\%])\end{array}$ & $\begin{array}{c}\text { Don't Know } \\
\text { (n [\%]) }\end{array}$ & \\
\hline Age & & & & .0009 \\
\hline $18-29$ & $127(67.6)$ & $88(57.5)$ & $177(78.0)$ & \\
\hline $30-39$ & $37(19.7)$ & $37(24.2)$ & $32(14.1)$ & \\
\hline $40-49$ & $24(12.8)$ & $28(18.3)$ & $18(7.9)$ & \\
\hline Race & & & & .0003 \\
\hline White & $105(56.2)$ & $76(49.7)$ & $164(72.9)$ & \\
\hline Black & $64(34.2)$ & $63(41.2)$ & $42(18.7)$ & \\
\hline Asian & $2(1.1)$ & $3(2.0)$ & $5(2.2)$ & \\
\hline Hispanic & $11(5.9)$ & $5(3.3)$ & $9(4.0)$ & \\
\hline Other & $5(2.7)$ & $6(3.9)$ & $5(2.2)$ & \\
\hline Salary & & & & .29 \\
\hline$<\$ 19,000$ & $37(19.7)$ & $28(18.7)$ & $40(17.7)$ & \\
\hline$\$ 19,001-\$ 50,000$ & $69(36.7)$ & $48(32.0)$ & $79(35.0)$ & \\
\hline$\$ 50,001-\$ 100,000$ & $51(27.1)$ & $50(33.3)$ & $54(23.9)$ & \\
\hline$>\$ 100,000$ & $31(16.5)$ & $24(16.0)$ & $53(23.5)$ & \\
\hline Education & & & & $<.0001$ \\
\hline Less than a high school diploma & $7(3.7)$ & $5(3.3)$ & $8(3.6)$ & \\
\hline High school graduate or GED & $115(61.2)$ & $92(60.1)$ & $174(77.7)$ & \\
\hline College graduate & $60(31.9)$ & $38(24.8)$ & $38(17.0)$ & \\
\hline Post-graduate degree & $6(3.2)$ & $18(11.8)$ & $4(1.8)$ & \\
\hline Insurance & & & & .81 \\
\hline None & $31(16.9)$ & $18(12.0)$ & $27(12.4)$ & \\
\hline Private & $110(60.1)$ & $101(67.3)$ & $142(65.1)$ & \\
\hline Medicaid & $4(2.2)$ & $6(4.0)$ & $6(2.8)$ & \\
\hline Medicare & $13(7.1)$ & $9(6.0)$ & $15(6.9)$ & \\
\hline Other & $25(13.7)$ & $16(10.7)$ & $28(12.8)$ & \\
\hline Religion & & & & .11 \\
\hline Catholic & $35(18.8)$ & $24(15.8)$ & $26(11.6)$ & \\
\hline Protestant & $118(63.4)$ & $93(61.2)$ & $153(68.0)$ & \\
\hline Jewish & $1(0.5)$ & $6(4.0)$ & $2(0.9)$ & \\
\hline Islam & $2(1.1)$ & $4(2.6)$ & $1(0.4)$ & \\
\hline Buddhism & $0(0.0)$ & $0(0.0)$ & $1(0.4)$ & \\
\hline Atheism & $3(1.6)$ & $1(0.7)$ & $5(2.2)$ & \\
\hline None & $17(9.1)$ & $17(11.2)$ & $19(8.4)$ & \\
\hline Other & $10(5.4)$ & $7(4.6)$ & $18(8.0)$ & \\
\hline Sexual orientation & & & & .22 \\
\hline Heterosexual & $177(95.2)$ & $139(92.7)$ & $220(97.4)$ & \\
\hline Homosexual & $6(3.2)$ & $6(4.0)$ & $2(0.9)$ & \\
\hline Bisexual & $3(1.6)$ & $5(3.3)$ & $4(1.8)$ & \\
\hline Marital status & & & & .02 \\
\hline Single & $116(61.7)$ & $78(51.0)$ & $165(73.3)$ & \\
\hline Married & $53(28.2)$ & $54(35.3)$ & $46(20.4)$ & \\
\hline Divorced & $5(2.7)$ & $7(4.6)$ & $7(3.1)$ & \\
\hline Widowed & $1(0.5)$ & $1(0.7)$ & $1(0.4)$ & \\
\hline Civil union & $1(0.5)$ & $0(0.0)$ & $0(0.0)$ & \\
\hline Living with a partner & $9(4.8)$ & $10(6.5)$ & $4(1.8)$ & \\
\hline Separated, anticipating divorce & $3(1.6)$ & $3(2.0)$ & $2(0.9)$ & \\
\hline
\end{tabular}




\begin{tabular}{|c|c|c|c|c|}
\hline \multirow[b]{2}{*}{ Variable } & \multicolumn{3}{|c|}{ Do You Want to Receive the HPV Vaccine? } & \multirow[b]{2}{*}{$P^{*}$} \\
\hline & $\begin{array}{c}\text { Yes } \\
(\mathrm{n}[\%])\end{array}$ & $\begin{array}{c}\text { No } \\
(\mathrm{n}[\%])\end{array}$ & $\begin{array}{l}\text { Don't Know } \\
\text { (n }[\%])\end{array}$ & \\
\hline \multicolumn{5}{|l|}{ Lifestyle practices } \\
\hline I wear a seatbelt & & & & .02 \\
\hline All of the time & $85(45.2)$ & $90(58.8)$ & $134(59.0)$ & \\
\hline Most of the time & $68(36.2)$ & $34(22.2)$ & $53(23.4)$ & \\
\hline Some of the time & $29(15.4)$ & $26(15.0)$ & $37(16.3)$ & \\
\hline Never & $6(3.2)$ & $6(3.9)$ & $3(1.3)$ & \\
\hline I use tobacco (cigarettes or other forms) & & & & .001 \\
\hline Regularly & $59(32.2)$ & $28(18.9)$ & $47(20.9)$ & \\
\hline Occasionally & $39(21.3)$ & $26(17.6)$ & $65(28.9)$ & \\
\hline Never & $85(46.5)$ & $94(63.5)$ & $113(50.2)$ & \\
\hline I drink alcohol & & & & .14 \\
\hline Regularly & $49(26.2)$ & $28(18.4)$ & $53(23.6)$ & \\
\hline Socially & $111(59.4)$ & $91(59.9)$ & $118(52.4)$ & \\
\hline In the past & $15(8.0)$ & $13(8.6)$ & $23(10.2)$ & \\
\hline Never & $12(6.4)$ & $20(13.2)$ & $31(13.8)$ & \\
\hline
\end{tabular}

${ }^{*}$ Value from $\chi^{2}$ tests.

$\mathrm{HPV}$, human papillomavirus.

ences for wanting to receive the HPV vaccine were seen for the variables of being sexually active, lifetime number of female sexual partners, oral sex, and frequency of sex. Men who wanted to be vaccinated were more likely to not be currently sexually active and men who were undecided about vaccination were most likely to be virgins $(P=$ .0008). Men with the greatest lifetime number of female sexual partners were most likely to want the vaccine $(P=.0004)$. Not engaging in oral sex was a positive correlate of vaccine acceptance $(P=$ $.045)$. Virgin men were most likely to be undecided about receiving the vaccine $(P=.028)$. No significant correlates for vaccine acceptance were found for the type of contraception or protection used or a history of genital warts.

Men's feelings and knowledge about HPV and the HPV vaccine were analyzed as correlates of HPV vaccine acceptance (Table 3). Five variables were found to be significant correlates of vaccine acceptance, worry about vaccine side effects, concern about vaccine safety, the importance of getting vaccines, familiarity with the HPV vaccine, and the importance of getting the HPV vaccine. Men desiring vaccination were more likely to be extremely worried about vaccine side effects $(P<.0001)$ and less likely to be not concerned at all about vaccine safety $(P<.0001)$. Those men not worried about vaccine side effects or vaccine safety were most likely to be undecided about being vaccinated. Men who feel it is extremely important to get vaccines were also more likely to want the vaccine $(P<$ .0001). Greater familiarity with HPV positively correlated with vaccine acceptance $(<.0001)$. Similarly, feeling it is extremely important to get the $\mathrm{HPV}$ vaccine positively correlated with desire to be vaccinated $(P<.0001)$.

Factors that may affect men's willingness to receive the HPV vaccine were also examined (Table 4). Men were more willing to be vaccinated if their doctor recommended it $(56.0 \%)$, if it was free $(51.4 \%)$, and if research proved the vaccine will be helpful for men (50.7\%). Other reasons are listed in Table 4.

\section{Discussion}

Men's correlates of HPV vaccine acceptance have not been previously determined. Some may argue that men do not need the HPV vaccine. These people may appreciate the burden of HPV disease in women but fail to understand the magnitude of HPV-related disease in men. However, there are several reasons why vaccinating boys and men against HPV can be beneficial. First, the vaccine can prevent many HPV-related conditions, including penile, anal, and head-and-neck neoplasias; genital warts; and recurrent respiratory papilloma- 


\begin{tabular}{|c|c|c|c|c|}
\hline \multirow[b]{2}{*}{ Variable } & \multicolumn{3}{|c|}{ Do You Want to Receive the HPV Vaccine? } & \multirow[b]{2}{*}{$P^{*}$} \\
\hline & $\begin{array}{c}\text { Yes } \\
\text { (n [\%]) }\end{array}$ & $\begin{array}{c}\text { No } \\
(\mathrm{n}[\%])\end{array}$ & $\begin{array}{c}\text { Don't Know } \\
\text { (n [\%] })\end{array}$ & \\
\hline Are you sexually active? & & & & .0008 \\
\hline Yes & $144(76.6)$ & $120(78.4)$ & $159(70.0)$ & \\
\hline Not currently & $36(19.2)$ & $20(13.1)$ & $31(13.7)$ & \\
\hline Never have been & $8(4.3)$ & $13(8.5)$ & $37(16.3)$ & \\
\hline How old were you when you first had sexual intercourse? & & & & .15 \\
\hline$<15$ & $25(14.0)$ & $15(10.7)$ & $28(15.0)$ & \\
\hline $15-18$ & $131(73.6)$ & $104(74.3)$ & $125(66.8)$ & \\
\hline $19-25$ & $22(12.4)$ & $19(13.6)$ & $34(18.2)$ & \\
\hline$>25$ & $0(0.0)$ & $2(1.4)$ & $0(0.0)$ & \\
\hline Male sexual partners (n) & & & & .94 \\
\hline 0 & $157(89.2)$ & $122(88.4)$ & $166(90.7)$ & \\
\hline$<5$ & $8(4.6)$ & $7(5.1)$ & $8(4.4)$ & \\
\hline $5-10$ & $4(2.3)$ & $5(3.6)$ & $3(1.6)$ & \\
\hline$>10$ & $7(4.0)$ & $4(2.9)$ & $3(3.3)$ & \\
\hline Female sexual partners (n) & & & & .0004 \\
\hline 0 & $6(3.4)$ & $4(2.9)$ & $2(1.0)$ & \\
\hline$<5$ & $45(25.3)$ & $60(43.2)$ & $90(48.4)$ & \\
\hline $5-10$ & $51(28.7)$ & $37(26.6)$ & $42(22.6)$ & \\
\hline$>10$ & $76(42.7)$ & $38(27.3)$ & $52(28.0)$ & \\
\hline \multicolumn{5}{|l|}{ What type of sexual activity do you have? } \\
\hline Oral & & & & .045 \\
\hline No & $48(26.7)$ & $32(22.5)$ & $31(16.2)$ & \\
\hline Yes & $132(73.3)$ & $110(77.5)$ & $161(83.8)$ & \\
\hline Vaginal & & & & .66 \\
\hline No & $14(7.8)$ & $12(8.5)$ & $20(10.4)$ & \\
\hline Yes & $166(92.2)$ & $130(91.5)$ & $173(89.6)$ & \\
\hline Anal & & & & .24 \\
\hline No & $144(79.6)$ & $123(86.6)$ & $157(81.4)$ & \\
\hline Yes & $37(20.4)$ & $19(13.4)$ & $36(18.6)$ & \\
\hline Other & & & & .80 \\
\hline No & $174(97.8)$ & $139(97.9)$ & $185(96.9)$ & \\
\hline Yes & $4(2.2)$ & $3(2.1)$ & $6(3.1)$ & \\
\hline How often do you have sex? & & & & .03 \\
\hline Never & $2(1.2)$ & $4(2.9)$ & $15(8.0)$ & \\
\hline Less than once a month & $29(16.8)$ & $26(18.7)$ & $28(14.9)$ & \\
\hline At least once a month & $49(28.3)$ & $28(20.1)$ & $43(22.9)$ & \\
\hline At least once a week & $93(53.8)$ & $81(58.3)$ & $102(54.3)$ & \\
\hline
\end{tabular}

${ }^{*}$ Value from $\chi^{2}$ tests.

$\mathrm{HPV}$, human papillomavirus.

tosis. By preventing these potentially life-threatening diseases and infections that produce significant morbidity, boys and men can live healthier lives. ${ }^{19}$ Prophylactic vaccination may also reduce health care costs for men. Moreover, by vaccinating boys and men in addition to girls and women, society and individuals benefit from herd immunity. A gen- der-neutral vaccination program to prevent HPV makes good sense.

With respect to age, younger men were more likely to be undecided about receiving the HPV vaccine and older men were more likely to not want the HPV vaccine. Education about HPV and the HPV vaccine will be critically important for young 


\begin{tabular}{|c|c|c|c|c|}
\hline \multirow[b]{2}{*}{ Variable } & \multicolumn{3}{|c|}{ Do You Want to Receive the HPV Vaccine? } & \multirow[b]{2}{*}{$P^{*}$} \\
\hline & $\begin{array}{c}\text { Yes } \\
(\mathrm{n}[\%])\end{array}$ & $\begin{array}{c}\text { Yes } \\
(\mathrm{n}[\%])\end{array}$ & $\begin{array}{c}\text { Yes } \\
(\mathrm{n}[\%])\end{array}$ & \\
\hline How worried are you about vaccine side effects? & & & & $<.0001$ \\
\hline Extremely worried & $41(21.8)$ & $37(24.2)$ & $10(4.4)$ & \\
\hline Neutral & $87(46.3)$ & $67(43.8)$ & $107(47.1)$ & \\
\hline Not worried at all & $60(31.9)$ & $49(32.0)$ & $110(48.5)$ & \\
\hline How concerned are you about vaccine safety? & & & & $<.0001$ \\
\hline Extremely concerned & $70(37.2)$ & $59(38.8)$ & $35(15.4)$ & \\
\hline Neutral & $82(43.6)$ & $59(38.8)$ & $35(15.4)$ & \\
\hline No concerned at all & $36(19.2)$ & $34(22.4)$ & $68(30.0)$ & \\
\hline How important is it for you to get vaccines? & & & & $<.0001$ \\
\hline Extremely important & $126(67.0)$ & $70(45.8)$ & $89(39.2)$ & \\
\hline Neutral & $59(31.4)$ & $72(47.1)$ & $121(53.3)$ & \\
\hline Not important at all & $3(1.6)$ & $11(7.2)$ & $17(7.5)$ & \\
\hline How familiar are you with HPV? & & & & $<.0001$ \\
\hline Very familiar & $32(17.1)$ & $10(6.5)$ & $10(4.4)$ & \\
\hline Somewhat familiar & $112(59.9)$ & $80(52.3)$ & $128(56.6)$ & \\
\hline Not at all familiar & $43(23.0)$ & $63(41.2)$ & $88(38.9)$ & \\
\hline How important is it for you to get the HPV vaccine? & & & & $<.0001$ \\
\hline Extremely important & $102(56.7)$ & $28(18.8)$ & $18(8.2)$ & \\
\hline Neutral & $76(42.2)$ & $93(62.4)$ & $178(81.3)$ & \\
\hline Not important at all & $2(1.1)$ & $28(18.8)$ & $23(10.5)$ & \\
\hline
\end{tabular}

*Value from $\chi^{2}$ tests.

$\mathrm{HPV}$, human papillomavirus.

men, those at greatest risk, to accept vaccination. Women are probably more familiar with HPV because of their frequent screening examinations for cervical cancer and the recent media publicity about the quadrivalent HPV vaccine. Like with older mid-adult women, more older men see no need for vaccination. ${ }^{16}$

In general, more white men were undecided about vaccination and a greater percentage of black men were opposed to vaccination. However, compared with white men a greater percentage of black men wanted to receive the vaccine. We cannot honestly explain these findings so must leave the rationale to speculation.

A greater amount of education correlated positively with a desire to receive the HPV vaccine. Men with a higher level of formal education were perhaps better able to understand their risk of infection and the importance of a prophylactic intervention. Although future HPV vaccine education should target all men, an emphasis on those without a college degree may be particularly beneficial.

Being single correlated positively with indecision about receiving the vaccine. Although marital
Table 4. Factors That Affect Men's Willingness to Receive the Human Papillomavirus Vaccine

\begin{tabular}{lc}
\hline $\begin{array}{l}\text { I would be more willing to } \\
\text { get the HPV vaccine ... }\end{array}$ & $\begin{array}{c}\text { Do you want to get the } \\
\text { HPV vaccine? (n [\%]) }\end{array}$ \\
\hline If my doctor recommend it & $250(43.9)$ \\
No & $319(56.1)$ \\
Yes & $276(48.5)$ \\
If free & $293(51.5)$ \\
No & $281(49.3)$ \\
Yes & $289(50.7)$ \\
If the research proved the vaccine to be helpful in men \\
No \\
Yes & $323(56.7)$ \\
If covered by insurance & $247(43.3)$ \\
No & $337(59.1)$ \\
Yes & $233(40.9)$ \\
If the research proved the vaccine to be safe in men \\
No \\
Yes \\
If my partner wanted me to get it \\
No \\
Yes \\
\hline
\end{tabular}

HPV, human papillomavirus. 
status is somewhat irrelevant to all other vaccination programs, we detected some hesitancy by unmarried men. Reluctance at the present time is justified given the lack of clinical trial data and approval by the FDA. A global vaccination policy for all boys, combined with ample education for men, may adequately address this current problem of indecision.

Health behaviors were also examined as correlates for vaccine acceptance. Use of a seat belt most of the time correlated positively with a desire for vaccination. Interestingly, men who wore seat belts all the time were more likely to be undecided about vaccination. Perhaps those most cautious about automobile safety were equally cautious about accepting a vaccine before reviewing safety and efficacy data in men. Men who used tobacco products regularly were more likely to want the vaccine. This group response is particularly encouraging because tobacco use has an adverse effect on the immune system's response to HPV infection. ${ }^{20}$ Smokers are less likely to clear HPV infection and have an increased risk for cervical neoplasia. ${ }^{21,22}$

Interesting correlates of vaccine acceptance were also seen when men's sexual history was examined. Men who were not currently sexually active were more likely to want the HPV vaccine. However, male virgins were more likely to be undecided about vaccination. In the former case, nonvirgins not currently sexually active perhaps were aware of potential risks and saw a window of opportunity to be protected. Unfortunately, male virgins did not fully comprehend the ideal time to be vaccinated was before initiating a sexual relationship. Although this may not pose difficulties for sexually naïve young boys receiving the HPV vaccine, it identifies a special educational challenge for vaccinating a catch-up population of male virgins. Men with a history of more than 10 female sexual partners were also more likely to want the HPV vaccine. Although this risk profile for potential existing HPV infection minimizes the possible attributes of the vaccine, these higher-risk men clearly appreciated the need for vaccination. Although not statistically significant, the same trend was noted for men who have sex with men. Men reporting 5 or fewer sexual partners were more likely to be undecided about receiving the vaccine. Once again, much education will be necessary for this population because vaccination would be more beneficial in this lower-risk group of men. Men who had oral sex were more likely to be undecided about vaccination, but men who had not had oral sex were more likely to want the HPV vaccine. No significant correlates were noted for a history of vaginal and anal sex. The implications for these types of sexual activity and desire to be vaccinated are not completely understood. With respect to sexual frequency, men who never had sex were more likely to be undecided about vaccination. Again, the virgins perhaps did not appreciate the same urgency for vaccination as sexually experienced men.

Several feelings toward all vaccines and the HPV vaccine and knowledge of HPV were found to correlate positively with HPV vaccine acceptance. Men who were extremely worried about vaccine side effects or extremely concerned about vaccine safety were more likely to want the HPV vaccine. These same men may have been extremely concerned or worried about the risks of HPV infection and, therefore, for them vaccination is preferable. Men who were not worried about the vaccine side effects nor concerned about vaccine safety were more likely to be undecided about receiving the HPV vaccine. These aloof men could also benefit from special education about receiving the HPV vaccine. Men who felt it extremely important to get vaccines, in general, also were most likely to want the HPV vaccine. This expected positive correlation helps to validate our survey. Those who felt it was unimportant to get vaccines were most likely to be undecided about HPV vaccination. Familiarity with HPV also correlated significantly with HPV vaccine acceptance. Men very familiar with HPV were most likely to want the HPV vaccine. Similarly, those men not familiar with HPV were more likely to be undecided about HPV vaccination. These data underscore the importance of educating men about HPV to insure a successful vaccine implementation program for men. As anticipated, men who felt it was extremely important to get the $\mathrm{HPV}$ vaccine were most likely to want to receive the HPV vaccine. Thus, educational efforts must convey the importance of receiving the HPV vaccine.

When asked which factors would most influence men to receive the HPV vaccine, more than half of the men stated they would be more inclined to receive the vaccine if recommended by a doctor. Parents of adolescents also indicated that a positive recommendation by their health care providers was 
the single most important factor in influencing them to vaccinate their children. ${ }^{23}$ Half of the men stated they would be more inclined to be vaccinated if research proved the vaccine to be helpful in men. With the absence of safety and efficacy data in men, availability of these data will be crucial to overall vaccine acceptance. Almost half of the men stated that they would be more likely to receive the vaccine if it were covered by insurance. The provision of this preventive health care measure by the insurance industry will also help successful implementation of the HPV vaccine among boys and men. In descending order of importance, men were clearly making their decision at this time based on expert opinion, research-based safety and efficacy, and financial cost. Cost, as in all medical decisions, plays a role in the decision process. We assume the cost for vaccinating men would be the same as the current expense of vaccinating women. Whether payers embrace HPV vaccination for men as readily as they have financial support for women is to be determined.

This study was limited by perhaps several underrepresented populations of men, including older men, Asians and Hispanics, men without medical insurance, and non-high school graduates. Men of certain faiths, homosexual men, and divorced men were also underrepresented. Other studies of these groups of men would be of value.

Our trial found many interesting correlates for HPV vaccination acceptance, refusal, and indecision. Men with greater general education, high-risk health behaviors, and knowledge about HPV are more likely to want the HPV vaccine. Because of the rather high rate of uncertainty among men, the availability of clinical research findings and a focused lay educational program should facilitate even wider HPV vaccine acceptance by men.

\section{References}

1. Villa LL, Costa RLR, Petta CA, et al. Prophylactic quadrivalent human papillomavirus (types 6, 11, 16 and 18) $\mathrm{L} 1$ virus-like particle vaccine in young women: a randomized double-blind placebo-controlled multicentre phase II efficacy trial. Lancet Oncol 2005;6:271-78.

2. The FUTURE II Study Group. Quadrivalent vaccine against human papillomavirus to prevent highgrade cervical lesions. N Engl J Med 2007;356:191527.

3. The FUTURE II Study Group. Effect of prophylactic human papillomavirus L1 virus-like-particle vaccine on risk of cervical intraepithelial neoplasia grade 2, grade 3 and adenocarcinoma in situ. A combined analysis of four randomized clinical trials. Lancet 2007;369:1861-8.

4. Garland SM, Hernandez-Avila M, Wheeler CM, et al. Quadrivalent vaccine against human papillomavirus to prevent anogenital diseases. N Engl J Med 2007;356:1928-43.

5. Nielson CM, Flores R, Harris RB, et al. Human papillomavirus prevalence and type distribution in male anogenital sites and semen. Cancer Epidemiol Biomarkers Prev 2007;16:1107-14.

6. Wiatrak BJ, Wiatrak DW, Broker TR, Lewis L. Recurrent respiratory papillomatosis: a longitudinal study comparing severity associated with human papilloma viral types 6 and 11 and other risk factors in a large pediatric population. Laryngoscope 2004; 114:1-23.

7. Maloney EM, Unger ER, Tucker RA, et al. Longitudinal measures of human papillomavirus 6 and 11 viral loads and antibody response in children with recurrent respiratory papillomatosis. Arch Otolaryngol Head Neck Surg 2006;132:711-5.

8. Abramowitz L, Benabderrahmane D, Ravaud P, et al. Anal squamous intraepithelial lesions and condyloma in HIV-infected heterosexual men, homosexual men and women: prevalence and associated factors. AIDS 2007;21:1457-65.

9. Cupp MR, Malek RS, Goellner JR, Smith TF, Espy MJ. The detection of human papillomavirus deoxyribonucleic acid in intraepithelial, in situ, verrucous and invasive carcinoma of the penis. J Urol 1995;154: 1024-9.

10. Gregoire L, Cubilla AL, Reuter VE, Hass GP, Lancaster WD. Preferential association of human papillomavirus with high-grade histologic variants of penile-invasive squamous cell carcinoma. J Natl Cancer Inst 1995;87:1705-9.

11. Malek RS, Goellner JR, Smith TF, Espy MJ, Cupp MR. Human papillomavirus infection and intraepithelial, in situ, and invasive carcinoma of the penis. Urol 1993;42:159-70.

12. Palefsky JM, Holly EA, Ralston ML, Jay N, Berry JM, Darragh TM. High incidence of anal high-grade squamous intraepithelial lesions among HIV-positive and HIV-negative homosexual and bisexual men. AIDS 1998;12:495-503.

13. Frish M, Glimelius B, van den Brule AJ, et al. Sexually transmitted infection as a cause of anal cancer. N Engl J Med 1997;337:1350-8.

14. Syrjanen S. Human papillomavirus (HPV) in head and neck cancer. J Clin Virol 2005;32:S59-66.

15. D'Souza G, Kreimer AR, Viscidi R, et al. Casecontrol study of human papillomavirus and oropharyngeal cancer. N Engl J Med 2007;356:1944-56.

16. Ferris DG, Waller JL, Owen A, Smith J. HPV vaccine acceptance among mid-adult women. J Am Bd Fam Med 2008;21:31-7. 
17. Ferris DG, Waller JL, Owen A, Smith J. Mid adult women's attitudes about receiving the prophylactic human papillomavirus vaccine. J Lower Genital Tract Dis 2007;11:166-72.

18. Ferris DG, Waller JL, Miller J, et al. Men's attitudes toward receiving the HPV vaccine. J Lower Genital Tract Dis 2008;12:276-81.

19. Dunne EF, Nielson CM, Stone KM, Markowitz LE, Giuliano AR. Prevalence of HPV infection among men: a systematic review of the literature. J Infect Dis 2006;194:1044-57.

20. Wiley DJ, Wiesmeier E, Masongsong E, et al. Smokers at higher risk for undetected antibody for oncogenic human papillomavirus type 16 infection. Cancer Epidemiol Biomarkers Prev 2006;15:915-20.
21. McIntyre-Seltman K, Castle PE, Guido R, Schiffman M, Wheeler CM, ALTS Group. Smoking is a risk factor for cervical intraepithelial neoplasia grade 3 among oncogenic human papillomavirus DNApositive women with equivocal or mildly abnormal cytology. Cancer Epidemiol Biomarkers Prev 2005; 14:1165-70.

22. Ferris DG, Hainer BL, Pfenninger JL, Zuber TJ. See and treat electrosurgical loop excision of the cervical transformation zone. J Fam Pract 1996;42: 253-7.

23. Davis K, Dickman ED, Ferris DG, Dias JK. Human papillomavirus vaccine acceptability among parents of 10 to 15 year old adolescents. J Low Genit Tract Dis 2004;8:188-94. 